\title{
Trends in NHP Research: Prospects and Challenges of Next Generation NHPs
}

\author{
Cory S. Harris, $\mathrm{PHD}^{1 *}$, John Thor Arnason, $\mathrm{PHD}^{1}$ \\ 'Biology Department, University of Ottawa, Ottawa K1N 6N5, Canada \\ *0 charris@uottawa.ca
}

KEYWORDS: Analysis; cannabis; extraction; future markets; natural health products; nutraceuticals

\section{Introduction}

Modern Natural Health Products (NHPs) are medicinal dosage forms also known and regulated variously as Dietary Supplements, Phytomedicines and Complementary and Alternative Medicines in different countries. Related regulated food products include Medicinal Foods, Supplemented Foods, Functional Foods, and Nutraceuticals, while cannabis products are regulated separately. All of the above are derived from or inspired by natural products that have existed for millennia. Most have been developed through ancient medical systems (e.g. Traditional Chinese Medicine and Ayurveda) and distinct indigenous cultures, which combine worldview, beliefs, practices, into "ways of knowing". Others were identified or advanced through scientific discovery and biotechnology. Together, they have contributed-and will continue to contribute-to human health and economy at a global scale.

Knowledge, practice and trade of NHPs and related products, however, are not static but dynamic. From traditional preparations to manufactured dosage forms, or extractives, they continue to evolve together with allied industry, regulations, and consumer preferences. With technological advances in agri-food and analytical sciences and global trends toward regulated cannabis markets, renewed interest and investment in research is fueling a new generation of products in a wide variety of formats for a wide variety of applications. At the same time, future research and development faces practical and ethical hurdles that must be addressed, namely the loss of biodiversity due to habitat destruction or climate change and the need to reconcile indigenous and non-indigenous ways, as well as allopathic and complementary medicine, particularly with respect to medicinal biodiversity.
For all areas of the world, advances in knowledge and technology coming, for example, from food and analytical sciences are helping to improve NHPs and related products and to provide evidence for their health benefits. Older technologies for production risked producing a less appealing product subject to solvent residues, partial oxidation, and loss of phytochemicals that have aroma and health benefits. Herb drying has moved from poorly conceived hot air driers or air drying to properly constructed herb dryers that ensure rapid air flow and drying at low temperature to preserve labile phytochemicals or other ingredients. Alternatively, many herbs are now processed fresh right out of the field. Previously, analytical techniques focused on only a few bioactives or marker compounds whereas current targeted and untargeted metabolomics platforms now provide a technicolour view of plant components that can be harnessed to identify bioactives and contaminants, authenticate resource materials, and optimize production practices [1-4]. Similarly, advancements in genomics and proteomics facilitate not only the elucidation and exploitation of biosynthetic pathways but the investigation of NHP effects in humans, experimental models, and in the plant (or other organism). Details of these recent developments in the field follow with emphasis on plant derived products.

\section{Changing Extraction and Transformation Technologies}

Extraction and transformation have improved greatly in recent years and these options have been scaled up and are now available commercially [5]. Accelerated Solvent Extraction (ASE) allows selection of pressure, temperature and solvent programing for highly reproducible controlled extractions. Subcritical Water Extraction occurs 
when water is used as the solvent at moderately high pressure and temperature, which increases the dielectric constant of water, and makes it very effective for extraction of phenolics in fruits and vegetables. Supercritical fluid extraction (SCE) using $\mathrm{CO}_{2}$ at temperatures and pressures where liquid, gas and solid co-exist is ideal for lipophilic compounds while leaving hydrophilic compounds behind. It provides a sterile, solvent-free extract with low risk of oxidation and is often used to make cannabis, lycopene, pepper and many other plant extracts. Wholespectrum extracts are achieved by Cold Finger Extraction that preserve as many as possible of the bioactives, especially aroma compounds in plants (for example ginger). The plant material is percolated by solvent (usually alcohol) in a reflux system at low temperature. The industrial production of fresh plant juices using a screw press yields a full spectrum juice that is immediately cooled and treated with alcohol to prevent bacterial growth. For Echinacea, this juice product preserves high molecular weight polysaccharides and glycoproteins with immunostimulant properties in human volunteers [6]. Microwave-assisted process (MAP), ohmic heating $(\mathrm{OH})$, pulsed electric field (PEF) or ultrasonic extraction (USE) are emerging technologies that will impact NHPs in the future. Unlike traditional solvent extraction (with the possible exception of Soxhlet), the examples above permit consistent, controlled extraction conditions with adjustable parameters for optimized recovery of desired metabolites. Most methods, moreover, require less use of hazardous solvents yet retain more bioactive and ephemeral compounds.

Solvent removal and/or recovery technologies have likewise become more efficient. The final stage of extract preparation involves removal of solvent and recovery of dried extract, often achieved with vacuum drying or freeze drying. At an industrial scale, spray drying or falling film applications are often used for large-scale extract drying, as these are cost effective and rapid.

Transformation of NHPs continues to evolve as well, building on both traditional practices such as fermentation and modern biotechnologies such as bioreactors. Fermentation has been traditionally used in Asian food and nutraceutical preparations including soya sauce, kimchi, and kombucha. With increased interest in the potential health benefits of fermented foods and health products, fermentation is now gaining popularity in North American NHP preparations [7-9]. With tissue culture, bioreactors and chemical inducers (of secondary metabolism), growing conditions (biotic and abiotic factors, treatments) can be manipulated to accelerate or slow development, enhance phytochemical and/or nutrient production, and improve product quality and stability.
As advances in extraction and transformation lead to new products with distinct chemical and pharmacological properties, advances in formulation and delivery of NHPs will lead to new product formats that promise to improve bioavailability, safety and efficacy [10-12]. While tinctures, ointments and other traditional preparations will not disappear anytime soon, the next generation of NHPs may include transdermal patches, subcutaneous implants, inhalers, and more.

\section{Advances in Analytical and Other Technologies}

Recent advances in analytical technologies, including the advent of metabolomic, chemometric and other omic technologies, have revolutionized research and now need to be integrated more fully into pharmacopeial and industry methods. Where, in the past, only a few targeted active principles or marker compounds were analysed by targeted HPLC or GC analysis, now hundreds of untargeted compounds can be detected and identified in plant tissues and extracts by LC- and GC-MS, as well as NMR, techniques. The metabolome analysed by MS or NMR metabolomics can reliably identify species and the presence of substituents (e.g. bioactives, nutrients), undeclared plant products, contaminants or adulterants. Practical industry guidance is provided through publication of validated methods such as the Botanical Adulterants Program [13]. Using multivariate statistical methods such as discriminant analysis and regression, metabolomic analysis can reveal markers of activity when compared to bioassay data $[14,15]$. For quality assurance work, quantitative NMR methods are now being developed that are much more accurate and transferable from facility to facility, than other methods, but low NMR sensitivity is still an issue limiting wide use.

Polypharmacy is a new treatment option, which uses the combined action of multiple active principles in extracts, for which a full analysis offered by metabolomics is required [16]. While genomic technologies had a controversial start in plant identity work with NHPs, more rigorous protocols are now available that are the latest methods of identity and authentication studies [17]. As well, novel delivery systems such as nanoparticles, phytosomes [18] are improving stability, bioavailability and other characteristics of NHP formulations.

\section{Riding the Cannabis Wave}

Cannabis is one of the world's oldest, most famous, and most widely used medicinal plants. Although cannabis products are not legally classified as NHPs or foods, they 
fit the scientific profile of these categories in most ways. Moreover, cannabis science of the past and present has relied heavily of knowledge and methods developed by NHP and food scientists. Today, the global trend toward regulated cannabis production and sale, particularly legalization in Canada and certain US states, has provided funds that stimulated an explosion in researchfrom plant biology and phytochemistry to processing and formulation to pre-clinical, clinical and social science. As this investment continues, advances in cannabis research and development (R\&D) stand to benefit and reshape the NHP landscape in multiple ways.

Cannabis is a versatile and genetically diverse crop with numerous potential applications and product types, all of which are of interest to industry. Leveraging genomics and analytics, cannabis $\mathrm{R} \& \mathrm{D}$ activities will seek to understand and improve/manipulate all aspects of plant growth and development (e.g. reproduction, secondary metabolism, stress tolerance) under different conditions (e.g. light, water, nutrients, endophytes) using different production and propagation systems (e.g. indoor, greenhouse, field, tissue and cell culture). We will similarly see improvements and innovation in harvest and post-harvest practices, as well as formulations and delivery formats, building on new and existing technologies (as discussed above) to maximize product quality and stability. Directly or indirectly relevant to other medicinal plants, all such advances in cannabis R\&D will spill over into the NHP sector, along with increased availability of infrastructure and trained professionals.

Beyond advances in research and manufacturing, the popularity of cannabis and the popularization of cannabis science may also offer additional advantage to NHPs. First, cannabis is a clear example of a medicinal plant that works, at least based on the experience of millions of patients and recreational users. While this is welcome news for an NHP industry plagued by a lack of clinical support, evolving approaches to cannabis clinical trials should provide new best practices applicable to NHPs. Second, cannabidiol (CBD) has emerged as a second bioactive compound with therapeutic potential that, unlike THC, does not cause inebriation. Given the popularity of CBD among different patient demographics, the potential transition of CBD regulation to a NHP-like framework would stimulate new investment into CBDcontaining NHPs formulated with other medicinal plants, vitamins, probiotics, etc. Culturally, the increasing level of public knowledge and understanding about cannabis should help educate consumers about NHPs, most of which-like cannabis - contain multiple, potentially interacting active ingredients.

\section{Challenges}

Most commercialized herbal medicines and medicinal foods are derived from, or inspired, by traditional indigenous knowledge. Historically and with very few exceptions, the indigenous knowledge holders and communities have received little recognition and no compensation while non-indigenous interests reaped all the benefits. With the Rio convention in 1992, and later with the Nagoya protocol, the world recognized the rights of developing countries and indigenous peoples to protect their biodiversity and medicinal knowledge. Now, rather than the colonial approach of exploiting ethnobotanical knowledge for commercial development of pharmaceuticals, collaborations between researchers and indigenous and ethnic communities are emerging to study health benefits of medicinal products for community health. The emphasis is on safety and efficacy studies of traditional medicines and foods that promote community engagement, respect indigenous concepts of disease, health and wellness, and translate traditional knowledge into a modern scientific context. Finally, "reinvention" of best practices of traditional medicine in public health strategies is being developed. An example of this is the re-integration of thoroughly studied traditional foods and medicines as a means of combatting the epidemic of type 2 diabetes in several First Nations in Canada. This approach, rather than commercialization of ethnobotanically important medicines, appears to be preferred by most indigenous groups. Should commercialization be pursued, fair and respectful benefit-sharing agreements must also be put in place [19].

The greatest challenge to NHPs worldwide is the loss of medicinal biodiversity due to habitat destruction caused by human conversion of ecosystems or by climate change [20]. Already 600 species of plants are extinct in modern times and thousands more are endangered. Traditional knowledge of biodiversity is being lost at an even greater pace. While some areas of the world, especially Asia, Europe and Africa, have embraced medicinal biodiversity research and use, the field lags behind in the Americas. Historic ethnobotanies record $>400$ medicinal species in Eastern Canada and $>20,000$ in North America, but only a small percentage of these have been examined by modern pharmacological and phytochemical methods. Will we study them before they are extirpated or finally extinct? As a consequence, it is key that NHP researchers make efforts in conservation and climate change, as well as health and socioeconomic equality, for example through collaboration with non-profit organizations. 
In Asia, Europe and Africa, NHPs are historically well integrated into modern health care. In the Americas, UK and Australia, they are only tolerated under strict legal conditions and generally their use is not supported by the majority of conventional (allopathic) health care providers. Many factors contribute to this divide, most notably the scarcity of high quality Phase 3 clinical trials. Because such trials are limited by challenges in trial design and high costs with lower return on investment, acceptance of NHP Research by the allopathic medical community is a continuing challenge. However, there is no question about public acceptance of NHPs (a multibillion dollar industry) as an unprecedented demand for them occurred this year during the Covid 19 pandemic [21]. NHP researchers agree that some of the recent outstanding evidence of health benefits of NHPs in the peer reviewed literature will both improve health and narrow the divide between complementary and allopathic medicine.

\section{List of Abbreviations Used}

CBD: cannabidiol

GC: gas chromatography

GC-MS: gas chromatography-mass spectrometry

HPLC: high pressure liquid chromatography

MAP: microwave assisted process

NHP: natural health product

NMR: nuclear magnetic resonance

$\mathrm{OH}$ : ohmic heating

PEF: pulsed electric field

SCE: supercritical fluid extraction

USE: ultrasonic extraction

\section{Conflicts of Interest}

JTA is a member of Souroubea Botanicals Inc. which produces botanicals for animal care. $\mathrm{CH}$ is a member of Ekidna Sensing Inc. which is developing technologies for cannabis sensing.

\section{Authors' Contributions}

Both authors contributed equally to concept, analysis and interpretation as well as drafting, final approval and agreements.

\section{References}

[1] Lopez-Sanchez P, De Vos RCH, Jonker HH, Mumm R, Hall RD, Bialek L, Leenman R, Strassburg K, Vreeken R, Hankemeier T, Schumm S, van Duynhoven J. Comprehensive metabolomics to evaluate the impact of industrial processing on the phytochemical composition of vegetable purees. Food Chemistry. 2015 Feb 1;168:348-55. https://doi.org/10.1016/j. foodchem.2014.07.076

[2] Sumner LW, Lei Z, Nikolau BJ, Saito K. Modern plant metabolomics: advanced natural product gene discoveries, improved technologies, and future prospects. Natural Product Reports. 2015;32(2):212-29. https:// doi.org/10.1039/c4np00072b

[3] Turi CE, Finley J, Shipley PR, Murch SJ, Brown PN. Metabolomics for phytochemical discovery: development of statistical approaches using a cranberry model system. Journal of Natural Products. 2015 Apr 24;78(4):953-66. https://doi.org/10.1021/np500667z

[4] Aliferis KA, Bernard-Perron D. Cannabinomics: application of metabolomics in cannabis (Cannabis sativa L.) research and development. Frontiers in Plant Science. 2020;11:554. https://doi.org/10.3389/fpls.2020.00554

[5] Harris CS, Vanderheyden T, Arnason JT. Extraction Technologies for Plant-derived Nutraceuticals and Natural Health Products. Nutraceuticals and Human Health: The Food-to-supplement Paradigm. Royal Society of Chemistry. 2020 Mar 17.

[6] Brovelli EA, Rua D, Roh-Schmidt H, Chandra A, Lamont E, Noratto, GD. Human gene expression as a tool to determine horticultural maturity in a bioactive plant (Echinacea purpurea L. Moench). Journal of Agricultural and Food Chemistry. 2005;53(21):8156-61. https://doi. org/10.1021/jf0505372

[7] Vuong T, Benhaddou-Andaloussi A, Brault A, Harbilas D, Martineau LC, Vallerand D, Ramassamy C, Matar C, Haddad PS. Antiobesity and antidiabetic effects of biotransformed blueberry juice in KKA (y) mice. International journal of obesity. 2009 Oct;33(10):1166-73. https://doi. org/10.1038/ijo.2009.149

[8] Marco ML, Heeney D, Binda S, Cifelli CJ, Cotter PD, Foligné B, Gänzle M, Kort R, Pasin G, Pihlanto A, Smid EJ, Hutkins R. Health benefits of fermented foods: microbiota and beyond. Current Opinion in Biotechnology. 2017 Apr 1:44:94-102. https://doi.org/10.1016/j. copbio.2016.11.010

[9] Rezac S, Kok CR, Heermann M, Hutkins R. Fermented foods as a dietary source of live organisms. Frontiers in Microbiology. 2018 Aug 24;9:1785. https://doi. org/10.3389/fmicb.2018.01785

[10] Muhamad N, Plengsuriyakarn T, Na-Bangchang K. Application of active targeting nanoparticle delivery system for chemotherapeutic drugs and traditional/ herbal medicines in cancer therapy: a systematic review. InternationalJournal ofNanomedicine. 2018;13:3921-35. https://doi.org/10.2147/IJN.S165210

[11] Byeon JC, Ahn JB, Jang WS, Lee SE, Choi JS, ParkJS. Recent formulation approaches to oral delivery of herbal 
medicines. Journal of Pharmaceutical Investigation. 2019 Jan 15;49(1):17-26. https://doi.org/10.1007/ s40005-018-0394-4

[12] Harwansh RK, Deshmukh R, Rahman MA. Nanoemulsion: Promising nanocarrier system for delivery of herbal bioactives. Journal of Drug Delivery Science and Technology. 2019 Jun 1;51:224-33. https://doi.org/10.1016/j. jddst.2019.03.006

[13] Cardellina II JH. Turmeric raw material and products laboratory guidance document. Austin, TX: ABC-AHPNCNPR Botanical Adulterants Prevention Program. 2020.

[14] Shang N, Saleem A, Musallam L, Walshe-Roussel B, Badawi A, Cuerrier A, Arnason JT, Haddad PS. Novel approach to identify potential bioactive plant metabolites: pharmacological and metabolomics analyses of ethanol and hot water extracts of several canadian medicinal plants of the cree of eeyou istchee. PLoS One. 2015 Aug 11;10(8):e0135721. https://doi.org/10.1371/ journal.pone.0135721

[15] Liu R, Burkett K, Rapinski M, Arnason JT, Johnson F, Hintz P, Baker J, Harris CS (in press). Biochemometric analysis of fatty acid amide hydrolase inhibition by Echinacea root extracts. Planta Medica. [accepted October 2, 2020].

[16] Chen Q, Lu X, Guo X, Guo Q, Li D. Metabolomics characterization of two Apocynaceae plants, Catharanthus roseus and Vinca minor, using GC-MS and LC-MS methods in combination. Molecules. 2017 Jun;22(6):997. https://doi.org/10.3390/molecules22060997

[17] Upton R, David B, Gafner S, Glasl S. Botanical ingredient identification and quality assessment: strengths and limitations of analytical techniques. Phytochemistry Reviews. 2019Jul 9;19:1157-77. https://doi.org/10.1007/ s11101-019-09625-z

[18] Patel J, Patel R, Khambholja K, Patel N. An overview of phytosomes as an advanced herbal drug delivery system. Asian Journal of Pharmaceutical Science. 2009 Apr;4(6):363-71.

[19] Schroeder D, Chennells R, Louw C, Snyders L, Hodges T. The rooibos benefit sharing agreement-breaking new ground with respect, honesty, fairness, and care. Cambridge Quarterly of Healthcare Ethics. 2019 Nov 5;29(2):285-301. https://doi.org/10.1017/ S0963180119001075

[20] Applequist WL, Brinckmann JA, Cunningham AB, Hart RE, Heinrich M, Katerere DR, van Andel T. Scientists' warning on climate change and medicinal plants. Planta Medica. 2020 Jan;86(1):10-18. https://doi. org/10.1055/a-1041-3406

[21] Raterman K. Herbal companies brace for supply chain impacts of Covid 19. HerbalGram 2020;126:66-74. 


\section{Article Information}

Managing Editor: Pierre Haddad, Kieran Cooley

Article Dates: Received Oct 15 20; Accepted Nov 12 20; Published Dec 0720

\section{Citation}

Please cite this article as follows:

Harris CS, Arnason JT. Trends in NHP Research: Prospects and Challenges of Next Generations NHPs. Journal of Natural Health Product Research. 2020 Dec 07: 2(2). https://jnhpresearch.com/index.php/jnhpr/article/view/13

DOI Link: https://doi.org/10.33211/jnhpr.13

\section{Copyright}

(c) Cory S. Harris, John Thor Arnason. (2020). Published first in the Journal of Natural Health Product Research. This is an open access article distributed under the terms of the Creative Commons Attribution License (https://creativecommons.org/licenses/by/4.0/), which permits unrestricted use, distribution, and reproduction in any medium, provided the original work, first published in the Journal of Natural Health Product Research, an NHP Publications journal, is properly cited. The complete bibliographic information, a link to the original publication on https://www.jnhpresearch.com, as well as this copyright and license information must be included.

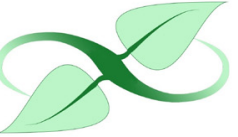

Canadà

Does the safety, efficacy, and quality of natural health products matter to YOU? Submit your research article to the Journal of Natural Health Product Research!

Pre-submission inquiries? Send us an email at editorial.office@jnhpresearch.com Facebook, Twitter and LinkedIn: @NHPPublications 